\title{
EL FEMINISMO (O LA AUSENCIA DEL MISMO) EN EL PENSAMIENTO POLÍTICO DE HANNAH ARENDT
}

\section{FEMINISM (OR THE LACK OF IT) IN HANNAH ARENDT“S POLITICAL THOUGHT}

\author{
Luisa Posada Kubissa \\ Universidad Complutense de Madrid \\ Iposada@filos.ucm.es
}

Recibido: febrero de 2018

Aceptado: junio de 2018

Palabras clave: Esfera privada, acción política, labor-trabajo, vita activa, crítica feminista.

Keywords: Private sphere, political action, labor-work, vita activa, feminist criticism.

Resumen: Hacerse la pregunta por el feminismo en el pensamiento político de Hannah Arendt implica aquí releer sus propuestas desde una óptica crítica. Frente a determinadas posiciones que han querido ver en esas propuestas aportaciones reutilizables para la orientación críticofeminista, lo que plantea este artículo es que las tesis arendtianas, y en particular su separación de los ámbitos privado y político, no pueden compadecerse con tal orientación. De entrada se atiende a cómo se piensa en Arendt esta separación de espacios, para analizar en un segundo momento por qué ello dificulta que se pueda hablar de feminismo en esta pensadora.

Abstract: To ask about feminism in Hannah Arendt's political thought implies here rereading its proposals from a critical point of view. Against certain positions which have wanted to see in these proposals reusable contributions for the critical-feminist orientation, what this article raises is that the Arendtian theses, and in particular their separation from the private and political spheres, can not sympathize with such orientation. At the beginning, we look at how Arendt thinks about this separation of spaces, to analyze in a second moment why this separation makes it difficult to talk about feminism in this thinker. 


\section{Sobre la diferenciación entre los espacios público y privado}

Gilligan, en su estudio empírico ${ }^{1}$, hablaba de una voz moral diferente, una voz femenina guiada por una ética relacional: "Frente a la pretensión de las teorías éticas universalistas contemporáneas (Kohlberg, Rawls o Habermas) de atender al punto de vista de un "otro generalizado", esto es, un abstracto cualquier otro, la «voz diferente» que Gilligan escuchaba en los discursos morales de las mujeres que entrevistó, y que no tiene por qué ser exclusiva de ellas, apunta a una comprensión de lo moral como respuesta a las otras existencias concretas, particulares, situadas, carnales, con sus necesidades, motivos, deseos, circunstancias" ${ }^{2}$. Ello implica hablar de una "ética del cuidado" que tradicionalmente se ha relegado al ámbito de la vida privada y que ha permitido conectar "las nociones de $\mathrm{H}$. Arendt acerca de la identidad narrativa de las existencias con la ética del cuidado de Gilligan, para resituar las nociones morales de autonomía y justicia en el marco de una exigencia —-también universal— de cuidado y de responsabilidad por las otras existencias" 3 .

1. Gilligan, C., In a Different Voice. Psychological Theory and Women's Development, Harvard University Press, Harvard, 1982 (Hay traducción como La moral y la teoría. Psicología del desarrollo femenino, F.C.E., México, 1985).

2. Muñoz Terrón, J. M., "Cuidar del mundo. Labor, trabajo y acción «en una compleja red de sostenimiento de la vida»", ISEGORÍA. Revista de Filosofia Moral y Política, $\mathrm{n}^{\mathrm{o}}$ 47, 2012, pp. 461480, p. 465.

3. Muñoz Terrón, J. M., op. cit., p. 466.
Esta actividad del cuidado nos hace pensar irremediablemente en lo que Arendt califica de "labor" en La condición humana, que incluye actividades como la de atender a la vida doméstica, o la de la reproducción, o la del cuidado de los animales para la subsistencia humana. Es cierto que Arendt no asigna estas funciones por sexo ${ }^{4}$, pero cabe preguntarse si ello no está implícito aquí, sobre todo si se atiende a lo que escribe sobre "la comunidad natural de la familia": "Resultaba evidente que el mantenimiento individual fuera tarea del hombre, así como propia de la mujer la tarea la supervivencia de la especie y ambas funciones naturales, la labor del hombre en proporcionar alimentación y la de la hembra en dar a luz, estaban sometidas al mismo apremio de la vida. Así pues, la comunidad natural de la familia nació de la necesidad, y ésta rigió todas las actividades desempeñadas en su seno" 5 .

Se ha interpretado que "los cuidados como ocupación y como preocupación desbordan el estrecho concepto arendtiano de labor para adquirir rasgos de las otras dos formas de vita activa, en tanto que correlato del cuidar es también conforme a la definición de Joan Tronto y Berenice Fisher de la que se ha partido- el mundo, la «mundanidad», con las consecuencias que ello tiene para el significado ético y político del cuidado" 6 . Pero esas mismas lecturas reconocen

4. Sánchez Muñoz, C., "Hannah Arendt", en M. J.Guerra, y A. Hardisson, Ana (eds.), 20 pensadoras del siglo $X X$, Tomo I, Ediciones Nobel, Oviedo, 2006, pp. 125-146, p. 129.

5. Arendt, H., La condición humana, Ediciones Paidós Ibérica, Barcelona,2005, p. 56 (The Human Condition, The University of Chicago Press, Chicago, 1958).

6. Muñoz Terrón, J. M., op. cit., 473. 
que la noción de labor arendtiana incluye su vinculación al campo de lo privado, concediendo que las tareas propias de la labor "no se pueden despojar de ese cierto carácter de carga y de ocultamiento que Arendt identifica con la labor y su adscripción a la invisibilidad (oscuridad) del ámbito «privado»"7.

La pluralidad es constitutiva de la condición humana y es lo que garantiza la libertad. Pero la pluralidad, y con ello el ejercicio de la libertad, se da para Arendt en la esfera de la acción, en el ámbito público: "La política trata del estar juntos y los unos con los otros de los diversos" 8 . Pero ocurre que "únicamente podemos acceder al mundo público común a todos nosotros, que es el espacio propiamente político, si nos alejamos de nuestra existencia privada y de la pertenencia a la familia a la que nuestra vida está unida" ${ }^{\text {. Es necesario }}$ que se dé la condición por la cual "política y libertad son idénticas"10, pero esa condición sólo es posible fuera del ámbito de lo privado-doméstico. La frontera entre los dos ámbitos se afianzó con la modernidad, ya que "Lo que ocurrió al iniciarse la Edad Moderna no fue que la función de la política cambiase, ni tampoco que se le otorgara de repente una nueva dignidad exclusiva. Lo que cambió más bien fueron los ámbitos que hacían parecer necesaria la política. El ámbito de lo religioso se sumergió en el espacio de lo privado mientras el ámbito de la vida y sus necesidades - para antiguos y medievales el privado par excellence- recibió una

7. Muñoz Terrón, J. M., ibid.

8. Arendt, H., ¿Qué es política?, Ediciones Paidós, Barcelona, 1997, p. 45. (Was ist Politik? Aus dem Nachlass, R. Piper GMBH \& Co KG, Munich, 1995).

9. Arendt, H., op. cit., p.74.

10. Arendt, H., op. cit., p.79. nueva dignidad e irrumpió en forma de sociedad en lo público"11.

Pueden darse para Arendt ejemplos de esta irrupción de la sociedad en lo público: "Ya el solo hecho de la emancipación de las mujeres y de la clase obrera, es decir, de grupos humanos a los que jamás antes se había permitido mostrarse en público, dan a todas las preguntas políticas un semblante radicalmente nuevo"12. Pero esta unión entre política y vida social supone "una contradicción interna que suprime y arruina lo específicamente político"13. Y Arendt piensa que lo arruina, porque el ámbito privado está sometido a la necesidad, donde no se da "la combinación específica de violencia y poder, combinación que sólo podía tener lugar en la esfera público-estatal porque sólo en ella los hombres actúan conjuntamente y generan poder"14. Así, las relaciones en el ámbito privado responden a la necesidad y no al juego de poder, pero esta tesis no se compadece con la realidad de una estructura desigual de poder entre los sexos en el ámbito privado y de su expresión brutal en forma de violencia de género. Si se entienden esas relacio-

11. Arendt, H., op. cit., p. 89.

12. Arendt, H., op. cit., p. 91.

13. Arendt, H., op. cit., p. 92.

14. Arendt, H., op. cit., p. 96. Aquí se entiende por "poder" en Arendt algo distinto de la noción weberiana, en el siguiente sentido: "Max Weber defined (Macht) as the possibility of forcing one's own will on the behavior of others. Hannah Arendt, on the contrary, understands power as the ability to agree upon a common course of action in unconstrained communication. Both represent power as a potency thai is actualized in action, but each takes a different model of action as a basis", en: Habermas, J. and McCarthy, T., "Hannah Arendt's Communications Concept of Power", Social Research, Vol. 44, No. 1, Hannah Arendt, spring 1977, pp. 3-24, p. 3. 
nes como resultantes de la necesidad, y no del poder, se impide de facto su posible transformación. Expulsada la violencia "del ámbito privado del hogar y de la esfera semipública de la sociedad"15, ésta queda invisibilizada y convertida en una coerción a la que, por ser de necesidad, no es posible resistirse. Esto es tanto como decir que "la justificación de lo que se considera político desde teorías como la arendtiana niega las condiciones sociales de injusticia (como la falta de redistribución y reconocimiento, los conflictos raciales y de género, etcétera) así como su posibilidad de ser discutidas en el espacio público"16.

Desde la tesis arendtiana de la tajante división entre lo privado-social y lo político se hace imposible alumbrar la desigualdad entre los sexos como una relación de poder, que sólo se daría en el ámbito público-político. Pero, en un párrafo de Los orígenes del totalitarismo, leemos que "Los que aspiran a la dominación total deben liquidar toda espontaneidad, tal como la simple existencia de la individualidad siempre engendrará, y perseguirla hasta en sus formas más particulares, sin importarles cuán apolíticas e innocuas puedan parecer"17. Y esto nos lleva a preguntarnos por la aniquilación de la individualidad que se produce como ejercicio de dominación en una esfera que Arendt entiende como apolítica.

15. Arendt, H., op. cit., pp. 95-6.

16. Gaytán, P., "Hannah Arendt y la cuestión social”, Sociológica, año 16, no 47, 2001, pp. 101128, p. 125.

17. Arendt, H., Los orígenes del totalitarismo, Grupo Santillana de Ediciones, Madrid,1974, p. 365. (The origins of the totalitarianism, Harcourt Brace Jovanovich, Inc., Nueva York, 1951).
La esfera política es, para Arendt, aquella donde se da la actividad por excelencia que es la acción. En ella aparecen la pluralidad y la individualidad, y la inserción en la misma es "como un segundo nacimiento", algo a lo que "no nos obliga la necesidad, como lo hace la labor, ni nos impulsa la utilidad como es el caso del trabajo"18. Este ámbito, marcado por el reconocimiento mutuo de la individualidad, es la expresión más digna de la vida activa, en tanto es expresión de la libertad como acción política, que presupone la igualdad de los diferentes. Pero nos preguntamos, ¿quiénes son los diferentes reconocidos aquí? ¿Acaso no quedan como idénticas, no individualizadas, aquellas que sólo pueden permanecer adscritas al ámbito privado del hogar y la familia?

Difícilmente podría defenderse la igualdad entre los sexos desde estos planteamientos. Quizá pudieran servir a un pensamiento que se planteara una ética femenina como ética ligada a los valores del cuidado y de la vida privada. Pero desde la tajante separación arendtiana de los ámbitos no político y propiamente político, en ningún caso se podrían politizar los conflictos del primero y, menos aún, darles una solución política. Sencillamente porque en Arendt no son conflictos políticos. De hecho, ser mujer, al ser una diferencia prepolítica, no puede ser trasladada al ámbito político: no es un problema político. De ahí que se haya podido afirmar que "esta exclusión de la lucha feminista del ámbito de lo político es lo que Adrienne Rich y posteriormente Mary O’Brien lamentaron en la década de 1970. A la pregunta: « ¿dónde quedan situadas las mujeres en la teoría política de Arendt?» estas autoras solo hallaban

18. Arendt, H., La condición humana, p. 206. 
respuesta en la caracterización de la labor y en la distinción entre lo público y lo privado establecidas en La condición humana. En esta obra las tradicionales tareas asignadas a las mujeres, tales como el cuidado y el sostenimiento de la vida, quedaban relegadas al devaluado ámbito de la necesidad, un ámbito considerado por Arendt como no político, privado, donde la violencia es un hecho casi natural" 19 . Sin embargo, ha habido quien, como Richard J. Bernstein, ha señalado que algunas lecturas feministas de finales de los años 90 detectaron en la idea arendtiana del "paria" un modelo que sirve como recurso para pensar la situación de las mujeres, de manera que reivindicaron su potencial para la crítica feminista: "Recently there have been more subtle feminist readings of her work in which there is an appropriation of the 'conscious pariah' as an exemplar of the situation of women who refuse to accept or assimilate to prevailing social relationships. There have been those who have argued that Arendt's conception of politics and public spaces provides the basis for rethinking the possibility of feminist politics. A vital current in recent feminist readings of Arendt is the view that her thinking provides critical resources which can potentially illuminate and contribute to feminist concerns"20.

Reivindicar el pensamiento arendtiano para una perspectiva política feminista es también lo que hace Anabella di Pego, cuando propone la lectura del ámbito público como un ámbito distinto y más amplio que el ámbito político en Arendt:

19. Birulés, F., Entreactos. En torno a la politica, el feminismo y el pensamiento, Katz Editores, Buenos Aires -Madrid, 2015, pp. 146-147.

20. Bernstein, R. J., Hannah Arendt and the Jewish Question, MA: MIT Press, Cambridge, 1996, p. 5.
"A partir de esta reconstrucción, la concepción del espacio público de Arendt puede dar cuenta de la crítica feminista que objeta la exclusión de las cuestiones privadas como objetos de debate del ámbito público. En la medida en que el espacio público no se define por los contenidos que en su interior se tematizan, nada queda excluido a priori del debate público, y en todo caso es en la misma arena pública donde se debe dirimir qué será objeto de debate y qué no. Por otra parte, es menester retomar los aportes de Fraser para dar cuenta de la otra crítica feminista, que señala que en el espacio público no son tanto los individuos sino más bien los grupos, quienes son protagonistas de las disputas. Por ello, es necesario concebir que existen diversos públicos en competencia, algunos subordinados y otros hegemónicos, que constituyen, a su vez, espacios públicos alternativos" 21. Pero lo que cabe discutir es si esos espacios públicos alternativos pueden traspasarse a la esfera política. Sobre todo, si tenemos presente la diferencia que la propia Di Pego adjudica a ambos espacios: "El surgimiento del espacio público constituye una posibilidad cuya concreción depende de la movilización de los hombres y de su capacidad de actuar en concierto, en tanto que el surgimiento del espacio político requiere, además, de una constitución -acto constituyente y marco legal-que reconozca a los hombres como

21. Di Pego, A., "Pensando el espacio público desde Hannah Arendt. Un diálogo con las perspectivas feministas", Questión. Revista Especializada en Periodismo y Comunicación, Vol. 1, Núm. 11, 2006, disponible en: http://perio.unlp. edu.ar/ojs/index.php/question/article/view/222 (consultado el 6-05-2018). 
iguales y como partícipes activos en los asuntos públicos"22.

Bonnie Honig ha señalado que Arendt no es una figura cómoda para una política feminista, precisamente por la rigidez de la distinción público/privado y porque "el problema de la mujer", en términos arendtianos, no era algo que se pudiera plantear políticamente ${ }^{23}$. Honig discute la interpretación de Seyla Benhabib, conforme a la cual habría en Arendt dos conceptos de ámbito público: uno "agonístico" y otro de carácter "asociativo". El primero se define por ser el espacio "en el que uno compite por el reconocimiento, la precedencia y la aclamación" y es, por tanto, "el espacio en el que se busca una garantía contra la futilidad y el paso de todas las cosas humanas". Por contraste, "la visión "asociativa» del espacio público sugiere que tal espacio emerge donde y cuando, en palabras de Arendt, "Ios hombres actúan juntos en concierto", un espacio en el que se puede dar la libertad y que "no es un espacio en ningún sentido topográfico o institucional"24. Esta lectura de Benhabib parece un intento para poder hacer emerger a las mujeres en lo público, en el segundo sentido, $y$ hacer posible que desde el pensamiento de Arendt puedan entenderse como partícipes de la libertad del espacio público en su dimensión "aso-

\section{Di Pego, A., ibídem}

23. Honig, B., "Toward an Agonistic Feminism: Hannah Arendt and the Politics of Identity", en J. Landes (ed.), Feminism, the Public and the Privat, New York, Oxford University Press, 1998, pp. 100-132.

24. Benhabib, S., El ser y el otro en la ética contemporánea. Feminismo, comunitarismo y posmodernismo, Gedisa Editorial, Barcelona, 2006, pp.109-110 (Situating the Self. Gender, Community, and Postmodernism in Contemporary Ethics,Polity Press in association with Blackwell Publishers Ltd., Cambridge,1992). ciativa", más allá de su adscripción a la necesidad propia de lo meramente privado. Pero Honig critica esta doble concepción de lo público en Arendt que Benhabib detecta, subrayando que la misma no se compadece con lo que realmente leemos si atendemos a sus propios textos ${ }^{25}$.

Cuando Nora Rabotnikof se ocupa del espacio público en la teoría política contemporánea ${ }^{26}$, dedica su IV capítulo a la idea de ese espacio en Arendt. Y ahí interpreta que, entendido el espacio público en Arendt desde una concepción "fenomenológica" como "ámbito de aparición"27, hay aquí una concepción fuerte del mismo: se trata de un lugar de lo común que tiene como característica consustancial el consenso dentro del pluralismo ${ }^{28}$. La cuestión será que, si como lo dice Rabotnikof, la concepción "fenomenológica" del espacio público hace hincapié en lo empírico o lo descriptivo ${ }^{29}$, podríamos interpretar que ese espacio se limita a dar cuenta de aquellos que tienen la capacidad de consensuar, esto es de los ciudadanos. Pero ¿qué pasa en el caso de quienes, como las mujeres, fueron excluidas históricamente de tal categoría? Cabría señalar que no pueden emerger en un espacio que se describe por lo que precisamente a ellas se lea ha negado: el reconocimiento de su individualidad, de su pluralismo o de su capacidad de consensuar entre iguales en competencia. Es decir, el sentido fuerte del espacio público

25. Honig, Bonnie, op. cit., p. 122.

26. Rabotnikof, N., En busca de un lugar común. El espacio público en la teoría política contemporánea, Instituto de Investigaciones Filosóficas-UNAM, México, 2005.

27. Rabotnikof, N., op. cit., p. 115.

28. Rabotnikof, N., op. cit., p. 117.

29. Rabotnikof, N., op. cit., p. 291. 
como lugar común no parece ser tan común para las mujeres.

Por otro lado, se ha reivindicado de Arendt el uso de la biografía, que coincidiría con la metodología feminista de rescatar a mujeres olvidadas: "la metodología arendtiana también encajaría perfectamente en los objetivos de la teoría feminista contemporáneas: nos permitiría reconstruir los fragmentos de las experiencias políticas de las mujeres que han sido silenciadas y olvidadas y que constituyen la memoria política de las vindicaciones y anhelos de las mujeres"30. Es el caso de la biografía que dedicó a la figura de Rahel Varnhagen, donde esta se incorpora al mundo político y de la acción. Al hablar de los encuentros posibles entre Arendt y el feminismo, Norma Villareal dice que "En primer lugar concentrémonos en aspectos metodológicos en la obra arendtiana. Ella hace del método del relato biográfico un elemento central para mirar una realidad a través de la vida de una persona". La biografía de Rahel Vernhagen, una mujer del siglo XIII, "coincide con el interés feminista de participar del proceso de la renovación historiográfica, apuntando a rescatar las historias de mujeres para hacerlas visibles, una historia desde las experiencias de los sujetos mujeres"31. Pero cabría interpretar que Arendt no pretendía con

30. Sanchez Muñoz, C., Hannah Arendt: El espacio de la política, Madrid, Centro de Estudios Políticos y Constitucionales, Madrid, 2003, p. 75. Para un más reciente y exhaustivo análisis del pensamiento de Hannah Arendt, recomendamos el título de la misma autora Arendt: estar (politicamente) en el mundo, Batiscafo, Valencia, 2015

31, Villareal Méndez, N., "Acercamiento a Hannah Arendt desde la teoría feminista del Género", (Documento de trabajo), Portal web Repositorio Institucional. Dirección Nacional de Bibliotecas. Universidad Nacional de Colombia, 2014, en: http://www.bdigital.unal.edu.co/39952/7/Acerca- esta biografía colaborar a la metodología feminista de visibilizar mujeres olvidadas, ni que pretendiera ir más allá del caso individual y concreto.

Una posible perspectiva feminista para las tesis de Arendt se resiente de su distinción entre acción y labor, de su tajante separación entre espacio público y ámbito de lo privado, de la exclusiva asignación de la libertad al primero, de la negativa a que lo privado pueda visibilizarse en la esfera de lo público. Pero una parte de la crítica feminista ha señalado que es posible resignificar conceptos arendtianos para esa orientación: "Queremos concluir este trabajo volviéndonos hacia la noción arendtiana de "pluralidad», que implica a la vez «igualdad y distinción» y que significa que vivimos siempre rodeados de nuestros semejantes, ante los cuales, al aparecer y mostrarnos por la palabra y la acción, devenimos realmente humanos y adquirimos nuestra identidad y unicidad. La pluralidad es además la fuente del poder, en la medida en que éste implica hablar y actuar juntos concertadamente en vista de un objetivo. Para el movimiento de mujeres esto significa que las individualidades sólo valen por y dentro de la pluralidad concreta a la cual pertenecen, que ambas, pluralidad e individualidad, persona y comunidad son imprescindibles para el buen funcionamiento de la actividad política"32.

Para poder entenderlo así, habría que convenir en que en Arendt la filosofía "no es una filosofía política, ni una filosofía de

miento $\% 20 \mathrm{a} \% 20$ Hannah\%20Arendt.pdf(Consultado: 08-05-2018).

32. Comesaña Santalices, "Lectura feminista de algunos textos de Hannah Arendt", Anales del Seminario de Historia de la Filosofía, vol. 18, 2001, pp. 125-142, p. 142. 
lo político, sino, primeramente, ante todo, una filosofía de la alteridad plural"33. Sólo por esta relectura se hace posible relativizar la frontera entre público y privado. Y sólo desde ahí es posible también repensar de otra manera la noción arendtiana de "natalidad": "La «natalidad" en tanto acción no es entonces un momento de la naturaleza sino aquello que lo interrumpe; de ahí que simbolice la capacidad de comienzo. Al mismo tiempo, si la acción está ahora ligada a lo privado, la línea divisoria de lo privado y lo público, si bien estaba firmemente definida al principio, se difumina, pierde su autoridad, cuando se trata de establecer las condiciones del mundo común y de la emergencia de un ser humano. La categoría arendtiana de «natalidad» combate la división tradicional entre lo privado y público, entre zôê y bio y, por ende, el espacio político entendido bajo el pretexto de la igualdad como la región de los mismos"34.

Pero cabe que nos preguntemos, como hace Seyla Benhabib, si la crítica de Arendt al "ascenso de lo social" en la modernidad, frente a la vida política griega, deja margen a que los esclavos, los trabajadores y las mujeres salgan del "oscuro interior del hogar" e irrumpan en la vida pública. Dicho de otro modo, la cuestión es si en Arendt es posible el proyecto de emancipación política de estos colectivos. Como Benhabib se interroga, cabe preguntarse si “¿La crítica de Arendt a este proceso es también una crítica del universalismo político como tal? ¿La «recuperación del espacio público» bajo las condiciones de la modernidad es

33. Collin, F., L'homme est-il devenu superflu? Hannah Arendt, Odile Jacob, París, 1999, p. 144.

34. Navarro González, O., "La natalidad como categoría filosófica en la obra de Hannah Arendt", Clepsydra, no 7, 2008, pp. 185-195, p. 193. necesariamente un proyecto elitista y antidemocrático que difícilmente pueda reconciliarse con la reivindicación de emancipación universal y la extensión universal de los derechos de ciudadanía que han acompañado a la modernidad desde las revoluciones estadounidense y francesa? “35. Estos recelos afectan de lleno a la concepción del feminismo como proyecto de emancipación.

\section{2. ¿Feminismo en Hannah Arendt?}

Como lo recoge su biógrafa Elisabeth Young-Bruehl, Arendt no tuvo interés en la causa feminista, ni mucho menos en las reclamaciones de igualdad entre los $\operatorname{sexos}^{36}$. Ello colaboró sin duda a que "las críticas vehementes y la falta de sintonía fue el arranque de las lecturas feministas de Hannah Arendt. En los años setenta y primeros ochenta el gran tema a debatir fue el "antifeminismo» de Arendt" ${ }^{37}$. Aun cuando en una reseña a Alice Rühle reconoce que las mujeres en el mundo contemporáneo tienen que "además del trabajo, hacerse cargo de la casa y cuidar de los niños"38, lo cierto es que sus palabras no dejan lugar a dudas: "En realidad, y a riesgo de parecerle anticuada, siempre he pensado que existían actividades determinadas que no convenían a las mujeres, que no les iban bien, si puedo expresarme así. Dar órdenes no

35. Benhabib, S., op. cit., p. 107.

36. Young-Bruehl, E., Hannah Arendt, Editorial Paidós, Barcelona, 2006, p. 311.

37. Guerra Palmero, M. J., "Arendt y los feminismos contemporáneos: ontología y política", Daimon. Revista Internacional de Filosofia, suplemento 4, 2011, pp. 203-212, p. 204.

38. Young-Bruehl, E., op. cit., p. 152. 
conviene a una mujer y es por ello por lo que debe esforzarse por evitar tales situaciones si quiere conservar sus cualidades femeninas"39. Estas afirmaciones avalan que se pueda aseverar que "Es evidente que no puede decirse de Hannah Arendt que fuese feminista, ni tampoco que le preocupase particularmente la problemática de la condición femenina en un mundo eminentemente patriarcal. Aunque en muchos casos pareció estar cerca de abordarla, pasó siempre sólo tangencialmente al lado de esta temática"40.

Preservar el orden privado y no reclamar su total politización ha sido leído, antes que como un error en Arendt, como un requisito positivo para evitar el autoritarismo sobrevenido en aquel, frente a la excesiva pretensión del feminismo contemporáneo por reclamar lo personal como político ${ }^{41}$. La separación entre la esfera pública y la esfera de lo privado no parece responder en Arendt, además, a una diferencia por género, sino más bien al ideal de la política de la antigua idea de la polis griega, concentrada en el bien común y en el entendimiento de los iguales: "La polis, propiamente hablando, no es la ciudad-estado en su situación física; es la organización de la gente tal como surge de actuar y hablar juntos, y su verdadero espacio se extiende entre las personas que viven juntas para este propósito, sin importar dónde estén"42. Ahora bien,

39. Arendt, H., "Seule demeure la langue materne1le", Revue Esprit, no 42, 6, 1980 (entrevista televisada de H. Arendt por Günter Gaus en la televisión alemana el 28 de octubre de 1964), p. 20.

40. Comesaña Santalices, G. M., op. cit., p. 126.

41. Benhabib, S., Hannah Arendt: Kein Herz für die Emanzipation? Seminararbeit, HumboldtUniversität zu Berlin (Institut für Kultur- und Kunstwissenschaften), Berlín, 2005, p. 40.

42. Arendt, H., La condición humana, p. 225. cabe preguntarse si este ideal no tiene como contrapartida el sometimiento de los no iguales y, con ello, la esclavización de quienes no juegan en el ámbito de la política.

Como ya se ha señalado aquí, una parte del pensamiento feminista actual ha querido rescatar y revalorizar el concepto arendtiano de "natalidad": "Nos encontramos, pues, con el concepto, la natalidad, que ha suscitado una mayor expectación por parte del feminismo filosófico y político, especialmente en la recepción francesa e italiana del pensamiento de Arendt. Desde estas lecturas, la natalidad ayudaría a poner en tela de juicio el sistema filosófico patriarcal desbaratando, de un solo golpe, su antropología, determinada por el privilegio de la mortalidad, y la inclinación ontológica y política hacia las abstracciones generalizadoras, que o bien son hueras o bien son totalizadoras, con la funesta tendencia de destruir la pluralidad humana y a declararla superflua. La vida humana, a la luz de la natalidad, es repensada desde un punto de vista relacional. Arribamos a una trama intersubjetiva, a un «mundo», y ahí se tejen las biografías de los individuos susceptibles de ser narradas "43. La natalidad implica un mundo que existe antes de nacer a él y que es "la condición prepolítica y prehistórica de la historia, la gran narración sin comienzo y sin fin" ${ }^{44}$. El ser humano con-vive e inter-actúa como un "quién" en el mundo que le pre-existe. Y, en ese sentido, "El milagro que salva al mundo, a la esfera de los asuntos humanos, de su ruina normal y «natural» es en último término el hecho de la natalidad, en el que se enraíza ontológicamente la facultad de la acción. Dicho con otras pa-

43. Guerra, M. J., op. cit., pp. 206-7.

44. Arendt, H., De la historia de la acción, Ediciones Paidós Ibérica, Barcelona, 1995, p.106. 
labras, el nacimiento de nuevos hombres y un nuevo comienzo es la acción que son capaces de emprender los humanos por el hecho de haber nacido" 45 .

Sobre la concepción arendtiana de la natalidad y el cuerpo, también hay discrepancias en las lecturas feministas. Así, mientras para Linda Zerillij6 la noción de nacimiento en Arendt va unida a la de mortalidad y no a la de género o identidad sexual, Tuija Pulkkinen entiende que el género y la identidad son indisociables de esa noción y, en ese sentido escribe: "Gender and identity belong without a doubt to Arendt's conception of 'birth'. An individual is from birth of a gender and of an ethnic origin. Natality, a person's beginning in the world as a separate body, is decisive and founding. A person constructs herself performatively, and leaves behind a story, but she is always bound to the fact of birth" 47 .

Se entienda como se entienda, lo cierto es que el nacimiento, en tanto "acción que son capaces de emprender los humanos", se distingue de la mera actividad social, en tanto que esta última es pura asociación que difiere radicalmente en Arendt de la capacidad y la organización política, con la que ha venido a confundirse: "Esta relación especial entre acción y estar juntos parece justificar plenamente la primitiva traducción del zoon politikon aristotélico por animal socialis (...). Más que cualquier elaborada teoría, esta inconsciente sustitución de lo social por lo político revela hasta qué punto se había

45. Arendt, H., La condición humana, p. 265.

46. Zerilli, L., "The Arendtian Body", en Honig, B.(ed.) Feminist Interpretations of Hannah Arendt, University Park, Pennsylvania State University Press, 1995, pp. pp. 167-193.

47. Pulkkinen, T., "Hannah Arendt and the Politics of Philosophy." Alternatives, 28, 2003, pp. 215-232, p. 225. perdido el original concepto griego sobre la política (...) Según el pensamiento griego, la capacidad del hombre para la organización política no sólo es diferente, sino que se halla en directa oposición a la asociación natural cuyo centro es el hogar (oikia) y la familia"48. La igualdad entre los iguales y la libertad no pueden darse en esa esfera regida por el hogar y la familia, sino que requieren de la esfera política: "La polis se diferenciaba de la familia en que aquélla sólo conocía «iguales», mientras que la segunda era el centro de la más estricta desigualdad. Ser libre significaba no estar sometido a la necesidad de la vida ni bajo el mando de alguien y no mandar sobre nadie, es decir ni gobernar ni ser gobernado. Así, pues, dentro de la esfera doméstica, la libertad no existía, ya que al cabeza de familia sólo se le consideraba libre en cuanto tenía la facultad de abandonar el hogar y entrar en la esfera política, donde todos eran iguales"49. La perversión de la frontera entre lo social y lo político, que viene a confundir la mera administración con la acción, es para Arendt un producto de la modernidad que altera así la deseable separación entre lo privado y lo público: "La emergencia de la sociedad - el auge de la administración doméstica, sus actividades, problemas y planes organizativos - desde el oscuro interior del hogar a la luz de la esfera pública, no sólo borró la antigua línea fronteriza entre lo privado y lo político, sino que también cambió casi más allá de lo reconocible el significado de las dos palabras y su significación para la vida del individuo y del ciudadano" 50 .

Pero ese "oscuro interior del hogar", que no debe ser alumbrado a la esfera pública,

48. Arendt, H., op. cit., pp. 51-2.

49. Arendt, H., op. cit., pp. 57-8.

50. Arendt, H., op. cit., p. 61. 
ha permanecido históricamente, lo quiera Arendt o no, como esfera domésticofamiliar a la que se asignan el trabajo productivo de los esclavos y el trabajo reproductivo de las mujeres. Por tanto, sólo el hombre - no esclavo y varón- se separa de esa esfera y puede entrar en la esfera de lo político. De este modo, la familia es categorizada como lo pre-político, lo que es el lugar de la desigualdad por necesidad natural y ámbito del trabajo para la supervivencia. Mezclar lo privado y la actividad con lo político y la acción es abrir la puerta a la aniquilación de la pluralidad y, con ello, a la posibilidad del totalitarismo. Contra este temor arendtiano se ha subrayado que, por el contrario, alumbrar a la luz pública cuestiones como "la educación de los niños, el cuidado de los enfermos, la atención a los jóvenes y mayores, la libertad de tener hijos, la violencia en la familia o el abuso infantil" significa abrirlos a la participación política y, por tanto "democratizarlos"51. Y, de este modo, contra Arendt puede afirmarse que "La distinción entre lo «social» y lo «político» no tiene sentido en el mundo moderno, no porque toda la política se haya vuelto administración y porque la economía se haya convertido en la quintaesencia de lo «público» como pensaba Hannah Arendt, sino primordialmente porque la lucha por hacer que algo sea público es una lucha por la justicia"52.

51. Benhabib, S., "Der empörende Unterschied: mit Hannah Arendt gegen Hannah Arendt denken”, Du: die Zeitschrift der Kultur, cuaderno 710, n 60 , Kulturmedien AG, Zürich, 2000, pp. 39-41, p. 41.

52. Benhabib, S., El ser y el otro en la ética contemporánea, p. 111.
A pesar de las reticencias que venimos sugiriendo para aceptar que haya una orientación feminista del pensamiento de Hannah Arendt, hay algo así como un "feminismo arendtiano", como el que representa en particular la filósofa Linda Zerilli. Esta autora "frente a la expresión del feminismo ligada a la preocupación por la igualdad y las políticas sociales, va a proponer que la política deriva del inter-esse, del espacio que conformamos entre todos a través del discurso, la acción, y que como características tiene la impredictibilidad y la contingencia. De hecho, asume como central el legado de la intersubjetividad pensada por Arendt, uno de los aspectos más celebrados desde toda lectura feminista de nuestra autora"53. Hay también una dirección feminista más ligada a la posmodernidad, que propone entrar en diálogo con Arendt y quiere vincular sus propuestas con un feminismo orientado a la deconstrucción de las identidades, a partir de la idea de la pluralidad como requisito para la acción ${ }^{54}$ . Superar la lectura feminista negativa de Arendt pasaría, para esta dirección, por la intelección arendtiana de la constitución del espacio político como acción entre los diversos, así como de esa acción como algo no reificado y, por lo mismo, contingente ${ }^{55}$. De este modo, ser quien es uno es no sería apelar a un fundamento de la acción y del hablar, sino a una performatividad de la acción que abre la puerta a una perspectiva feminista posmoderna en

53. Guerra, M. J., op. cit., p. 209.

54. Kahlert, H. y Lenz, C. (eds.), Die Neubestimmung des Politischen. Denkbewegungen im Dialog mit Hannah Arendt, Ulrike Helmer Verlag, Konigstein/Taunus, 2001.

55. Hark, S., Deviante Subjekte. Die paradoxe Politik der Identität, Leske und Budrich, Opladen, 1996, p. 155. 
tanto que crítica a la identidad. Y, con ello, se situaría a Arendt en el diálogo-puente entre modernidad y posmodernidad.

Sin embargo, pensamos que, para un pensamiento crítico-feminista, subsiste el problema de la división entre esfera privada y esfera pública y la arendtiana reclamación de que no debe desdibujarse la frontera entre ellas. Arendt advierte que, de darse ese debilitamiento fronterizo, se produciría la perversión y la destrucción de lo político ${ }^{56}$. Y lamenta que las modernas sociedades de masas, con su creciente conformismo, destruyan el mundo en común y también el ámbito público y el privado. Y esto sería incompatible con un discurso y una reivindicación feministas, que han reclamado y reclaman las relaciones privadas de los sexos como relaciones de poder y exigen para las mismas soluciones políticas.

El silencio casi total de Arendt acerca de la situación de desigualdad femenina conduce, como lo ha señalado Benhabib, a una paradoja inmediata en su pensamiento: "una se ve confrontada desde el principio con una paradoja: la autoconciencia de Hannah Arendt como judía, y su creencia de que ser judío en el siglo xx se ha convertido en una posición "política» inevitable en agudo contraste con su casi total silencio acerca de la cuestión femenina. En tanto que el destino de los judíos en el siglo xx está en el centro de su pensamiento público-político, su identidad como mujer y las dimensiones sociopolíticas y culturales de ser mujer en este mismo siglo, carecen de un reconocimiento explícito en su trabajo teórico"57. Pero, como la misma Benhabib argumen-

56. Hark, S., op. cit., p. 93.

57. Benhabib, S., "La paria y su sombra: sobre la invisibilidad de las mujeres en la filosofía política ta, volverse hacia Arendt y hacerlo desde la perspectiva crítico-feminista, es aplicar la hermenéutica en el más profundo de los sentidos. Así, entiende que Arendt habla también como mujer, por ejemplo, cuando escribe la biografía intelectual de Rahel Varnhagen y se propone contar su vida como ella misma la habría contado ${ }^{58}$ : "La vida de Rahel Levin Varnhagen estuvo llena de historias de amores fracasados, promesas rotas y compromisos infructuosos. Al darse a sí misma al hombre correcto, Rahel confiaba en conseguir el «mundo» que le era negado como judía y como mujer"59.

Pero, a pesar de esa huella de la conciencia de ser mujer que Benhabib detecta en la biografía de Rahel Varnhagen, lo cierto es que Arendt piensa el espacio público como el espacio "agonista" y no meramente "asociativo". Es el espacio en el que se da la lucha por el reconocimiento entre los individuos, que son diversos y que compiten entre sí. Pero es imposible entender la separación de espacios político-privado, que Arendt lamenta que se haya perdido, sin referirse a su concepto de "vita activa". Por este concepto distingue en La condición humana entre las actividades de la labor, el trabajo y la acción. Habla Arendt de actividades humanas diversas, como la labor, que responde a la actividad para la supervivencia y la satisfacción de las necesidades vitales; el trabajo, que consiste en la transformación

de Hannah Arendt", Revista Internacional de Filosofia Politica, UNED, nº 2, 1993, pp. 21-35, p. 21.

58. Arendt, H., Rahel Varnhagen. The Life of a Jewish Woman, Harcourt, Brace and Company, Nueva York / Londres, 1974-edición revisada (trad. castellana de Daniel Najmías, Rahel Varnhagen. Vida de una mujer judia, Lumen, Barcelona,2000).

59. Benhabib, S., op. cit., p. 28. 
de la naturaleza por el proceso productivo del ser humano; y la acción, por la que los seres humanos actúan en común. La distinción entre labor y trabajo radica en que "signo de todo laborar es que no deja nada tras de sí, que el resultado de su esfuerzo se consume casi tan rápidamente como se gasta el esfuerzo. Y, no obstante, dicho esfuerzo, a pesar de su futilidad, nace de un gran apremio y está motivado por su impulso mucho más poderoso que cualquier otro, ya que de él depende la propia vida"60. Frente a la labor, "el trabajo de nuestras manos, a diferencia del trabajo de nuestros cuerpos -el homo faber que fabrica y literalmente «trabaja sobre» diferenciado del animal laborans que labora y «mezcla con»-, fabrica la interminable variedad de cosas cuya suma total constituye el artificio humano"61. Pero además de estas actividades humanas, y habría que decir que por encima de ellas, está "El discurso y la acción (que) revelan esta única cualidad de ser distinto. Mediante ellos, los hombres se diferencian en vez de ser meramente distintos; son los modos en que los seres humanos se presentan unos a otros, no como objetos físicos, sino qua hombres. Esta apariencia diferenciada de la mera existencia corporal se basa en la iniciativa, pero en una iniciativa que ningún ser humano puede contener y seguir siendo humano. Esto no ocurre en ninguna otra actividad de la vita activa"62. En esta última actividad se da el poder, entendido no como sometimiento o dominación, sino como potencia del actuar en común: "El poder, sin embargo, es la única fuerza que emana de la acción y proviene de la mutua gestión de grupos de seres humanos: una vez en acción, se

60. Arendt, H., La condición humana, pp. 111-2. 61. Arendt, H., op. cit., p. 165.

62. Arendt, H., op. cit., p. 206. puede hacer que sucedan cosas, y así el poder se convierte en fuente de un tipo distinto de "fuerza»"63. Este poder, como potencia, como acción, se da en el espacio político, en el que los iguales son iguales precisamente porque reconocen sus diferencias. El poder no puede darse en el espacio privado-doméstico, en el que reina la indiferenciación. Pero cabe preguntarse si esa concepción del espacio privado, que tradicionalmente ha sido asignado a las mujeres, no hace que el mismo se haya constituido por ello como el espacio de quienes no resultan discernibles.

\section{Para unas breves conclusiones}

En Arendt el espacio privado queda definido como esfera de la necesidad, frente a la esfera política que es el espacio de la libertad y la acción. Esta conceptualización arendtiana nos hace concluir que, desde ahí, no es posible pensar el ámbito privado y familiar como resultado del ejercicio político de la dominación patriarcal. Y, con ello, estaríamos ante una propuesta que resulta incompatible con una mirada crítico-feminista que se propone la transformación política de esa dominación ancestral. Porque desde la perspectiva feminista, sólo la politización de las relaciones privado-domésticas puede sacar a la luz las relaciones de desigualdad entre los sexos y permitir, de este modo, democratizarlas. De otro modo, la división de espacios y de actividades relegaría irremediablemente a las mujeres al ámbito privado-doméstico, a la actividad de la labor y, por lo mismo, las excluiría de la participación en lo propiamente 63. Benhabib, S., El ser y el otro en la ética contemporánea, p. 110. 
humano: la política, la acción. Y, con ello, se imposibilitaría el proyecto de emancipación que el feminismo es.

De modo que las consideraciones que hemos presentado sobre el pensamiento político de Arendt parecen conducir a la idea de que el feminismo está ausente del mismo. Por otra parte, cabe también concluir que, como hemos visto, para Arendt el ascenso de lo social, frente a la vida política griega, tuvo como efecto la emancipación de las mujeres, de los esclavos, de los trabajadores, sacándolos de lo que para Arendt es "el oscuro interior del hogar" y haciendo que entraran en la vida pública, cosa que consideró de manera muy negativa. Si ello es así, podemos recordar las preguntas que Benhabib formula sobre si la crítica arendtiana al espacio público de la modernidad implica también la crítica al universalismo político ${ }^{64}$.

Habría que meditar sobre ello, pero, si la respuesta es afirmativa, cabría entender que las tesis arendtianas resultarían problemáticas para un discurso de emancipación universal como el discurso feminista. No obstante, creemos que la potencia del pensamiento arendtiano no puede desdeñarse sin más para un discurso tal, si bien ello exige una resignificación y una labor hermenéutica en profundidad de ese pensamiento para llevarlo a un lugar para el que, indudablemente, no fue elaborado.

\section{Bibliografía}

Arendt, H., Rahel Varnhagen. The Life of a Jewish Woman, Harcourt, Brace and Company, Nueva York / Londres, 1974-edición revisada (trad. castellana de Daniel Na-

64. Benhabib, Seyla, El ser y el otro en la ética contemporánea, p. 107. jmías, Rahel Varnhagen. Vida de una mujer judía, Lumen, Barcelona, 2000).

Arendt, H., Los orígenes del totalitarismo, Grupo Santillana de Ediciones, Madrid, 1974 (The origins of the totalitarianism, Harcourt Brace Jovanovich, Inc., Nueva York, 1951).

Arendt, H., "Seule demeure la langue maternelle", Revue Esprit, n 42, 6, 1980 (entrevista televisada de H. Arendt por Günter Gaus en la televisión alemana el 28 de octubre de 1964).

Arendt, H., De la historia de la acción, Ediciones Paidós Ibérica, Barcelona, 1995.

Arendt, H., ¿Qué es política?, Ediciones Paidós, Barcelona, 1997 (Was ist Politik? Aus dem Nachlass, R. Piper GMBH \& Co KG, Munich, 1995).

Arendt, H., La condición humana, Ediciones Paidós Ibérica, Barcelona,2005 (The Human Condition, The University of Chicago Press, Chicago, 1958).

Gaytán, P., "Hannah Arendt y la cuestión social", Sociológica, año 16, n 47, 2001, pp. 101-128.

Benhabib, S., "La paria y su sombra: sobre la invisibilidad de las mujeres en la filosofía política de Hannah Arendt", Revista Internacional de Filosofía Política, UNED, $n^{\circ} 2$, 1993, pp. 21-35.

Benhabib, S., "Der empörende Unterschied: mit Hannah Arendt gegen Hannah Arendt denken", Du: die Zeitschrift der Kultur, cuaderno 710, $n^{\circ}$ 60, Kulturmedien AG, Zürich, 2000, pp. 39-41.

Benhabib, S., Hannah Arendt: Kein Herz für die Emanzipation? Seminararbeit, Humboldt-Universität zu Berlin (Institut für Kultur- und Kunstwissenschaften), Berlín, 2005.

Benhabib, S., El ser y el otro en la ética contemporánea. Feminismo, comunitarismo y posmodernismo, Gedisa Editorial, 
Barcelona, 2006 (Situating the Self. Gender, Community, and Postmodernism in Contemporary Ethics, Polity Press in association with Blackwell Publishers Ltd., Cambridge,1992).

Bernstein, R. J., Hannah Arendt and the Jewish Question, MA: MIT Press, Cambridge, 1996.

Birulés, F., Entreactos. En torno a la política, el feminismo y el pensamiento, Katz Editores, Buenos Aires -Madrid, 2015.

Collin, F., L'homme est-il devenu superflu? Hannah Arendt, Odile Jacob, París, 1999.

Gilligan, C., In a Different Voice. Psychological Theory and Women's Development, Harvard University Press, Harvard, 1982 (Hay traducción como La moral y la teoría. Psicología del desarrollo femenino, F.C.E., México, 1985).

Comesaña Santalices, "Lectura feminista de algunos textos de Hannah Arendt", Anales del Seminario de Historia de la Filosofía, vol. 18, 2001, pp. 125-142.

Navarro González, O., "La natalidad como categoría filosófica en la obra de Hannah Arendt", Clepsydra, n 7, 2008, pp. 185195.

Guerra Palmero, M. J., "Arendt y los feminismos contemporáneos: ontología y política", Daimon. Revista Internacional de FiIosofía, suplemento 4, 2011, pp. 203-212. Habermas, J. and McCarthy, T., "Hannah Arendt's Communications Concept of Power", Social Research ,Vol. 44, No. 1, Hannah Arendt, spring 1977, pp. 3-24.

Hark, S., Deviante Subjekte. Die paradoxe Politik der Identität, Leske und Budrich, Opladen.

Honig, Bonnie: "Toward an Agonistic Feminism: Hannah Arendt and the Politics of Identity", en Landes, Joan (edited), Feminism, the Public and the Privat, New York, Oxford University Press, 1998, pp. 100-132.
Kahlert, H. y Lenz, C. (eds.), Die Neubestimmung des Politischen. Denkbewegungen im Dialog mit Hannah Arendt, Ulrike Helmer Verlag, Konigstein/Taunus, 2001.

Muñoz Terrón, J. M., "Cuidar del mundo. Labor, trabajo y acción «en una compleja red de sostenimiento de la vida»", ISEGORÍA. Revista de Filosofía Moral y Política, n 47, 2012, 4pp. 61-480.

Pulkkinen, T., "Hannah Arendt and the Politics of Philosophy." Alternatives, 28, 2003, pp. 215-232.

Rabotnikof, N., En busca de un lugar común. El espacio público en la teoría política contemporánea, Instituto de Investigaciones Filosóficas-UNAM, México, 2005.

Sanchez Muñoz, C., Hannah Arendt: El espacio de la política, Centro de Estudios Políticos y Constitucionales, Madrid, 2003. Sánchez Muñoz, C., "Hannah Arendt", en M. J. Guerra, y A. Hardisson, Ana (eds.), 20 pensadoras del siglo XX, Tomo I, Ediciones Nobel, Oviedo, 2006, pp. 125-146.

Villareal Méndez, N., "Acercamiento a Hannah Arendt desde la teoría feminista del Género", (Documento de trabajo), Portal web Repositorio Institucional. Dirección Nacional de Bibliotecas. Universidad Nacional de Colombia, 2014, en: http://www. bdigital.unal.edu.co/39952/7/Acercamiento\%20a\%20Hannah\%20Arendt.pdf Young-Bruehl, E., Hannah Arendt, Editorial Paidós, Barcelona, 2006.

Zerilli, L., "The Arendtian Body", en Honig, B.(ed.) Feminist Interpretations of Hannah Arendt, University Park, Pennsylvania State University Press, 1995, pp. 167-193. 